\title{
Aha! Insight experience correlates with solution activation in the right hemisphere
}

\author{
EDWARD M. BOWDEN and MARK JUNG-BEEMAN \\ Northwestern University, Evanston, Illinois
}

\begin{abstract}
In one experiment, we tested for an association between semantic activation in the right hemisphere $(\mathrm{RH})$ and left hemisphere ( $\mathrm{LH})$ and the Aha! experience when people recognize solutions to insight-like problems. The compound remote associate problems used in this experiment sometimes evoke an Aha! experience and sometimes do not. On each trial, participants $(N=44)$ attempted to solve these problems and, after $7 \mathrm{sec}$, named a target word, made a solution decision, and rated their insight experience of recognizing the solution. As in prior studies, the participants demonstrated more solution priming for solutions presented to the left visual field-RH (lvf-RH) than for solutions presented to the right visual field-LH (rvf-LH). As was predicted, following unsolved problems the participants showed greater priming for solutions that they rated as evoking an insight experience on the subsequent solution decision than for solutions that did not evoke an insight experience. This association was stronger for solutions presented to the lvf-RH than for those presented to the rvf-LH. These results tie the subjective experience of insight to an objective measure - semantic priming-and suggest that people have an Aha! experience in part because they already had semantic activation that could lead them to recognize the solution quickly. We believe semantic activation in both hemispheres cooperatively contributes to problem solving, but weak solution activation that contributes to the Aha! experience is more likely to occur in the RH than in the LH.
\end{abstract}

Most people have had the Aha! experience of insight many times for trivial problems such as riddles or crossword clues or when, at long last, they achieve a deep understanding of a vexing problem. However, because it depends so heavily on subjective experience, a deeper understanding of the processes underlying insight has been elusive. Researchers agree that when trying to solve an insight problem solvers (1) come to an impasse, perhaps because they are misled by ambiguous information in the problem (Dominowski \& Dallob, 1995; Smith 1995); (2) often cannot report the processing that enables them to overcome this impasse (Gick \& Lockhart, 1995; Ohlsson, 1992; Schooler \& Melcher, 1995); and (3) experience their solutions as sudden and surprising (Bowden, 1997; Davidson, 1995; Metcalfe, 1986a, 1986b; Metcalfe \& Wiebe, 1987; Schooler, Ohlsson, \& Brooks, 1993).

The experience of insight has been examined with feeling-of-knowing ratings, warmth ratings, and intuitions (Bowden, 1997; Davidson, 1995; Dorfman, Shames, \& Kihlstrom, 1996; Metcalfe, 1986a, 1986b; Metcalfe \& Wiebe, 1987; Seifert, Meyer, Davidson, Patalano, \& Yaniv, 1995). These approaches have helped characterize the insight experience, yet each has the shortcoming of relying

Research and writing were supported by NIDCD/NIH Grants R29 DC 02160 and R01 DC 04052 to M.J.B. Data were collected while both authors were at Rush Medical College, Chicago, IL. Correspondence concerning this article should be addressed to E. M. Bowden or M. JungBeeman, Department of Psychology, Northwestern University, 2029 Sheridan Rd., Evanston, IL 60208-2710 (e-mail: e-bowden@ northwestern.edu or mjungbee@northwestern.edu). solely on participants' subjective reports. The present experiment links participants' subjective judgments of insight with an objective measure of processing: specifically, priming for the solution.

\section{Subjective Experience of Insight}

When people attempt to solve noninsight problems, they generally give gradually increasing warmth ratings, indicating that they believe they are approaching a solution (warmth is a measure of how close one feels one is to reaching a solution); in contrast, when people attempt to solve insight problems, they report no change in warmth until immediately before solving the problem, when feelings of warmth increase dramatically (Metcalfe, 1986a). This pattern may be interpreted as supporting the ideas that solving insight problems requires reinterpretation of these problems and that solving such problems can sometimes (but not always) be relatively easy once the correct solution path is chosen (Schooler, Fallshore, \& Fiore, 1995). Furthermore, solvers are better at predicting whether they will eventually achieve solutions of noninsight problems than they are at predicting solutions of insight problems (Metcalfe \& Wiebe, 1987), possibly due to initial misinterpretation of the problem.

Why do problem solvers sometimes have the Aha! experience of insight upon reaching a solution? Solvers seem to experience insight when they suddenly overcome an impasse as a result of some unconscious processing, often termed restructuring (for a review, see Dominowski \& Dallob, 1995), but this begs the question of how restructuring occurs. Verbalizing solution attempts can actually impede 
successful solution of insight problems (see, e.g., Schooler et al., 1993), perhaps because it causes solvers to focus on their initial representation(Schooler et al., 1995). If difficulty in solving insight problems stems from failure to recognize solution-relevant features, the experience of insight might arise when those features are suddenly recognized - that is, when activation of such features suddenly surpasses a conscious threshold.

In Maier's (1931) classic study, when people solved insight problems after an indirect hint was provided, solvers who reported experiencing their solutions as a sudden insight did not report any awareness of the hint, whereas solvers who produced their solutions piecemeal uniformly reported using the hint to reach the solution. Similarly, when trying to solve anagrams, solvers' speed, accuracy, and subjective experience of solution are all affected by hint words presented too briefly to be identified, but that apparently elicit some semantic activation (Bowden, 1997). Furthermore, incorrect solution attempts are often semantically related to the correct solution (Bowers, Regehr, Balthazard, \& Parker, 1990), suggesting that solutionrelevant information was influencing solution attempts. People might have the Aha! experience when they have solution-relevant activation below the threshold of awareness prior to producing the solution.

Solvers appear to have solution-related semantic activation for insight-like problems they have not solved (Beeman \& Bowden, 2000; Bowden \& Beeman, 1998). Problem solvers manifest solution priming for yet-to-besolved compound remote associate problems (similar to some items on the remote associates test; Mednick, 1962), in which solvers must produce a solution word (e.g., sweet) that can form compounds with each of three problem words (e.g., tooth, potato, and heart). After working on these problems but failing to solve them, solvers read aloud solution target words faster than unrelated target words (Beeman \& Bowden, 2000; Bowden \& Beeman, 1998). A somewhat similar approach has shown that feeling-ofknowing for unanswered fact questions is associated with subsequent solution priming (Yaniv \& Meyer, 1987; but cf. Connor, Balota, \& Neely, 1992).

We propose that people have an Aha! experience when they suddenly recognize that some information, which they have already semantically activated, either is the solution or points to the solution path. The suddenness suggests that the solution-related activation was previously below the threshold of awareness, perhaps overshadowed by other activation not related to the solution. This account jibes with the consensus view that insight problems misdirect solvers to consider unhelpful information or solution paths: Some misdirected activation may be stronger than activation of solution-related concepts. Only when strong misdirected activation subsides can solutionrelated activation surpass the threshold of consciousness and be recognized. In contrast, for noninsight problems, solvers' strongest initial activation is probably solutionrelated, and they simply need to carry out operations to achieve solution (Schooler et al., 1995).
Most previous studies of the insight experience have involved insight problems typically fitting the criteria outlined above and fundamentally defined by the fact that they evoke an Aha! experience. In these studies, it is then described how solvers subjectively experience such problems differently than they would noninsight problems (i.e., problems that do not evoke insight). We used problems that sometimes evoke insight and sometimes do not. We then used insight ratings to assess how prior processing (i.e., semantic activation) differs for problems that evoke feelings of insight versus those that do not.

\section{Hemispheric Differences}

An intriguing question regarding insight solutions is whether hemispheric differences in patterns of semantic activation might interact to foster solution. We are not implying that either hemisphere alone is responsible for solving insight problems; rather, we propose that the right hemisphere $(\mathrm{RH})$ engages in cognitive processes that specifically facilitate solving such problems.

The literature on hemispheric differences in semantic priming to linguistic stimuli, and the theory that the $\mathrm{RH}$ engages in relatively coarse semantic coding whereas the left hemisphere (LH) engages in fine semantic coding, lead us to predict an RH advantage in solution priming for insight problems. We provide synopses of the theory and the evidence below; in-depth reviews are available elsewhere (e.g., Beeman, 1998; Beeman, Bowden, \& Gernsbacher, 2000; Beeman \& Chiarello, 1998; Beeman et al., 1994; Burgess \& Simpson, 1988; Chiarello, 1998; Chiarello, Burgess, Richards, \& Pollock, 1990; M. Faust \& Chiarello, 1998; Koivisto, 1997; Titone, 1998).

According to the RH coarse semantic coding theory, soon after encountering a word the RH engages in coarse semantic coding, weakly and diffusely activating alternative meanings and more distant associates, whereas the LH engages in relatively fine semantic coding, strongly focusing activation on a single interpretation of a word and a few close or contextually appropriate associates (Beeman et al., 1994; Burgess \& Simpson, 1988; Chiarello et al., 1990; M. Faust \& Chiarello, 1998; M. E. Faust \& Gernsbacher, 1996; Koivisto, 1997; Nakagawa, 1991; Titone, 1998).

For comprehension of most direct language, LH fine semantic coding has a clear advantage. For comprehension of indirect language such as jokes, metaphors, and inferences, additional semantic coding by the RH may be necessary (for a review, see Beeman, 1998). This may account for RH advantages in priming for target words related to predictive inferences (Beeman et al., 2000) or related to contextually inappropriate meanings of ambiguous words in sentences (Titone, 1998). RH coarse semantic coding may also account for increased neuroimaging signal in the $\mathrm{RH}$ for comprehension of metaphoric sentences over literal sentences (Bottini et al., 1994), processing of connected over unconnected discourse (Robertson et al., 2000), and integration of themes in untitled texts (St. George, Kutas, Martinez, \& Sereno, 1999). Damage to the RH system may account for the difficulties that RH-damaged patients 
have in understanding jokes (Bihrle, Brownell, Powelson, \& Gardner, 1986; Brownell, Michel, Powelson, \& Gardner, 1983), metaphors (Winner \& Gardner, 1977), and connotative meanings (Brownell, Potter, Michelow, \& Gardner, 1984), or in drawing inferences (Beeman, 1993; Brownell, Potter, Bihrle, \& Gardner, 1986).

Similarly, solving insight problems often requires secondary or tertiary interpretations of words and concepts or information that initially seems only distantly related to the problem, and might benefit from RH coarse semantic processing (Beeman \& Bowden, 2000; Bowden \& Beeman, 1998; Fiore \& Schooler, 1998).

In our previous experiments (Beeman \& Bowden, 2000; Bowden \& Beeman, 1998), solvers working on compound remote associate problems revealed different patterns of semantic activation in the LH and RH. Solvers initially show solution priming for targets presented to either visual hemifield, but after they work on the problem for 7 or $15 \mathrm{sec}$, solution priming is strongly maintained for lvf-RH target words but fades for rvf-LH target words. Moreover, when making solution decisions after 7 or $15 \mathrm{sec}$ of solving effort, solvers respond more quickly to lvf-RH target words than to rvf-LH target words. This is a striking result, given the ubiquitous rvf-LH advantage for responding to words, and suggests that, for insight problems, solutionrelated activation in the RH is useful at least for recognizing solutions, and may play a role in generating them.

\section{EXPERIMENT}

The following experiment tests for a relation between solution-related semantic activation, as indexed by priming, and feelings of insight that accompany solution recognition. The participants attempted compound remote associate problems, named solution (or unrelated) words, made solution decisions, and then rated the insight experience of their solution recognition. If solvers experience insight because existing semantic activation is suddenly recognized as pointing toward the solution, then they should show greater solution priming on trials for which they experience insight for their subsequent solution decisions. Also, as in prior experiments (Beeman \& Bowden, 2000; Bowden \& Beeman, 1998), solvers should manifest stronger solution priming and make faster solution decisions for lvf-RH target words than for rvf-LH target words.

\section{Method}

Participants. Forty-four students (31 women and 13 men) at the University of Wisconsin at Parkside participated in the experiment for partial course credit. All the participants were strongly righthanded according to a brief handedness questionnaire and were native speakers of American English.

Materials. The problems were 144 compound remote associate problems (Beeman \& Bowden, 2000; Bowden \& Beeman, 1998; Bowden \& Jung-Beeman, in press) patterned after some items in the remote associates test (Mednick, 1962), which have been used to examine creativity, problem solving, and insight (see Dorfman et al., 1996). Test problems contained three words, each of which could form a compound word or phrase with the solution word (e.g., palm/shoe/house-TREE). These problems sometimes evoke feelings of insight and sometimes do not.

Procedure. Trials began with a central fixation cross presented on a computer screen, followed by three problem words presented simultaneously in horizontal orientation above, at, and below fixation. The participants tried to produce the solution within $7 \mathrm{sec}$; after the time limit, or sooner if they stated the solution, the problem words were erased, a tone sounded for $250 \mathrm{msec}$, and the fixation cross reappeared for $500 \mathrm{msec}$ (total stimulus onset asynchrony [SOA] = $7,750 \mathrm{msec}$ ). Then, a target word was presented horizontally for $180 \mathrm{msec}$, with the inner edge $1.5^{\circ}$ of visual angle from fixation. ${ }^{1}$

The target word was replaced by a letter-fragment pattern mask that remained on the screen for $120 \mathrm{msec}$. The participants had $3 \mathrm{sec}$ from the offset of the mask to name (i.e., read aloud) the target word. Half of the target words were solution words and half were unrelated words; half of each of these groups was presented to the left visual hemifield, and the other half to the right. The unrelated target words were the solutions to problems 72 trials away (e.g., the Problem 1 occurred with either its own solution or the solution to Problem 73). The participants saw each target word only once over the course of the experiment. Across participants, condition of target words was rotated so that all target words occurred equally often as both solutions and unrelated words and in both visual hemifields.

After the participants had named the target word, the experimenter pressed a key to record whether the response was correct. Immediately following the experimenter's response, the word SOLUTION? was presented, and the participants indicated whether the target word was indeed the solution (15 participants responded verbally, 14 responded with a right-hand buttonpress, and 15 responded with a left-hand buttonpress; there were no effects of response mode). Response time (RT) from the onset of the event until the participant responded was recorded. Finally, the word RATING? was presented with the rating scale of $1-5$ underneath. ${ }^{2}$ Ample time and care were taken to describe appropriate ratings to the participants. Examples of the Aha! experience were described. Awareness of decision processes (such as using a strategy) was emphasized as a criterion for lowinsight ratings, and lack of awareness ("I just knew, I don't know how I knew") was emphasized as the criterion for high-insight ratings. The ratings were further described roughly along the following lines:

A rating of 1 means that at first, you didn't know whether the word was the answer, but after thinking about it strategically (for example, trying to combine the single word with each of the three problem words) you figured out that it was the answer. A rating of 3 means that you didn't immediately know the word was the answer, but you didn't have to think about it much either. A rating of 5 means that when you saw the word you suddenly knew that it was the answer ("It popped into my head"; "Of course!" "That's so obvious"; "It felt like I was already thinking that"). Ratings of 2 and 4 indicate feelings somewhere in between. It is up to you to decide what rating to give each of your responses. There are no right or wrong answers.

Twenty-six participants used the above scale, and 18 used the reverse scale; there were no effects of scale direction. The participants were tested individually, with their chins positioned in a chinrest so that their heads were held steady and at a constant distance from the computer monitor. They were given five practice problems with target words.

\section{Results}

On average, the participants solved $19.4 \%(S D=6.0)$ of the problems within the 7-sec time limit and correctly named $90.2 \%$ ( $S D=6.8$ ) of the brief, lateralized target words. The data from 6 participants were replaced: 4 solved few problems $(>2.5 S D$ s below the mean-i.e., fewer than $4.75 \%), 1$ had few response latencies recorded $(>2.5 S D \mathrm{~s}$ 
below the mean-i.e., RTs recorded on fewer than $73 \%$ of the trials), and 1 showed very slow naming latencies and hyperpriming ( $>300 \mathrm{msec}$ of priming, $>2.5 S D$ s above the mean), suggesting strategic naming. The main effects and effects replicating earlier results are discussed after the novel analysis of insight rating data.

Insight ratings and the relation to solution priming. The main focus of this experiment was to determine whether the participants' feelings of insight, as indexed by the rating scale, had to do with solution-related activation, as indexed by solution priming (naming solutions faster than naming unrelated target words) for problems they had not yet solved. All trials on which the problem was solved during the 7-sec time limit were excluded from the analysis. ${ }^{3}$ We examined the relation between insight ratings that the participants gave for their correct solution decisions (i.e., hits) and the solution priming manifest when they named targets on those trials. Only ratings by hemifield cells for which a participant had two or more valid latencies were considered. Data from 2 additional participants were removed because they had fewer than five hits, and data from 2 others were removed because they assigned a single rating to nearly all the trials. Figure 1 shows solution priming in each hemisphere for trials assigned each insight rating by the remaining 40 participants.

To compare the insight-priming relation across hemispheres, a Pearson correlation between insight rating scores and priming ${ }^{4}$ was calculated for each hemifield for each participant. This gave a measure, for each participant, of whether his or her priming scores in each hemifield were related to his or her idiosyncratic use of the rating scale. Correlations were predicted to be low, because there were few observations per hemifield $\times$ rating condition cell and because semantic activation is just one component contributing to both the RT and the insight rating; moreover, semantic activation in either hemisphere could presumably affect insight ratings, whereas priming was assessed in only one hemifield on each trial. These correlation coefficients were then $z^{\prime}$-transformed (Cohen $\&$ Cohen, 1983). A positive correlation would reveal that the participants showed more priming for solution words that subsequently elicited a feeling of insight for their solution decisions. The participants' $z^{\prime}$-transformed correlation coefficients were entered into a $t$ test, which revealed that, on average, the participants' insight ratings correlated better with solution priming for lvf-RH targets (average $z^{\prime}=.178, S E=0.040$ ) than for rvf-LH targets [average $\left.z^{\prime}=.048, S E=0.041, t(39)=2.3, p<.03\right]$.

Because only 8 participants used every insight rating often enough to have more than two observations per hemifield $\times$ rating condition cell, an overall analysis of variance (ANOVA) was untenable. Given the reliable hemispheric difference in priming-insight correlations and a priori hypotheses, paired $t$ tests were used to compare rvf-LH and lvf-RH priming at each rating level (for participants who had data in both cells, leaving $n \mathrm{~s}$ of 11 , $23,37,37$, and 27 for ratings of 1, 2, 3, 4, and 5, respectively). These contrasts revealed a reliable lvf-RH advantage in solution priming only on trials for which the participants rated their solution decisions as most insightful [rating of 5: 40-msec lvf-RH advantage, $t(26)=5.2, p=$ .03 ; rating of $4: 63-\mathrm{msec}$ lvf-RH advantage, $t(36)=3.6$, $p<.07 ;$ at all other ratings, $t \mathrm{~s}<1]$.

\section{Data Replicating Results of Previous Experiments}

Naming latency. When the participants failed to solve problems within $7 \mathrm{sec}$, they named target words presented to the rvf-LH $21 \mathrm{msec}$ more quickly than target words presented to the lvf-RH $[F(1,43)=4.0, p=.05]$. See Table 1 for mean naming latencies of the 44 participants. The participants also showed priming, naming solution target words $55 \mathrm{msec}$ more quickly than they named unrelated target words $[F(1,43)=45.9, p<.0001]$. The participants showed reliable priming $(70 \mathrm{msec})$ for lvf-RH solution words $[F(1,43)=48.4, p<.0001]$ and for rvf-LH solution words [39 msec; $F(1,43)=11.1, p<.002]$. Most importantly, a reliable target type $\times$ hemifield $\times$ relatedness interaction reflected a $33-\mathrm{msec}$ RH advantage in solution priming $[F(1,43)=4.4, p=.04]$.

When the participants solved problems, they named rvf-LH target words 44 msec more quickly than lvf-RH

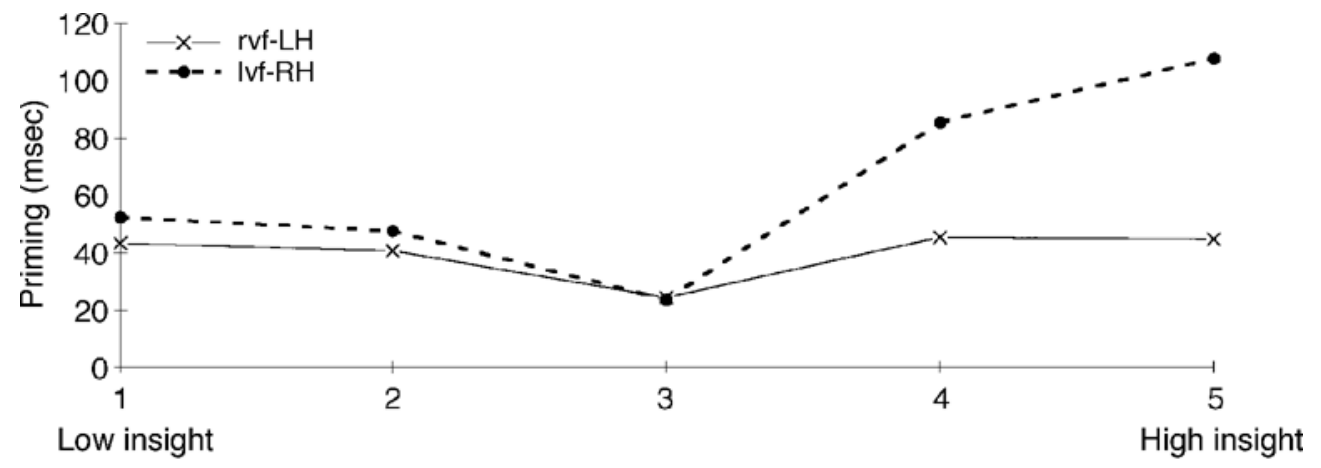

Insight rating for solution recognition

Figure 1. Mean priming (naming latency for solution words minus latency for unrelated words, in msec) by insight rating and hemifield of target word. 
Table 1

Mean Naming Latencies (in Milliseconds) and Standard Errors (SEs) Following Solved and Unsolved Problems

\begin{tabular}{|c|c|c|c|c|c|c|c|c|}
\hline \multirow[b]{3}{*}{ Target Type } & \multicolumn{4}{|c|}{ Solved } & \multicolumn{4}{|c|}{ Unsolved } \\
\hline & \multicolumn{2}{|c|}{ rvf-LH } & \multicolumn{2}{|c|}{ lvf-RH } & \multicolumn{2}{|c|}{ rvf-LH } & \multicolumn{2}{|c|}{ lvf-RH } \\
\hline & Mean & $S E$ & Mean & $S E$ & Mean & $S E$ & Mean & $S E$ \\
\hline Unrelated & 730 & 20 & 803 & 27 & 784 & 25 & 821 & 27 \\
\hline Solution & 682 & 25 & 697 & 30 & 745 & 21 & 751 & 24 \\
\hline Priming & 48 & & 106 & & 39 & & 70 & \\
\hline
\end{tabular}

target words $[F(1,43)=9.8, p<.005$; see Table 1]. They also showed priming, naming solution target words $79 \mathrm{msec}$ more quickly than they named unrelated target words $[F(1,43)=18.6, p<.0001]$. The participants showed reliable solution priming (106 msec) for lvf-RH target words $[F(1,43)=19.0, p<.0001]$ and for rvf-LH target words [48 msec; $F(1,43)=5.1, p<.03$ ]. A target type $\times$ hemifield of presentation $\times$ relatedness interaction reflected a 66-msec priming RH advantage for solution priming $[F(1,43)=4.7, p<.04]$.

Solution decision latency. We examined solution decision latencies only for trials on which the participants had already correctly named the target words, and only following unsolved problems. See Table 2 for mean decision latencies from 42 participants (data from the 2 participants with fewer than five hits were removed, as has been noted above). There was a main effect of response type: The participants made hit responses (responding "yes" when the target word was the solution) $245 \mathrm{msec}$ more quickly than they made correct rejections [responding "no" when the target word was not the solution; $F(1,43)<$ $5.7, p<.03]$. The participants responded $67 \mathrm{msec}$ more quickly to words presented to the lvf-RH than they did to words presented to the rvf-LH $[F(1,43)=2.1<.16]$. Response type and hemifield of presentation did not interact $[F(1,43)<1]$. The $\mathrm{RH}$ advantage in solution decision latencies, reliable in previous experiments, was not reliable here, perhaps because decisions were delayed until after solvers named the target words and the experimenter scored their responses.

Solution decision accuracy. When the participants correctly named the target words following unsolved problems, they made subsequent solution decisions as accurately for lvf-RH targets $(85.8 \%)$ as for rvf-LH targets $(86.4 \% ; t<1$; see Table 2$)$. Moreover, a sensitivity analysis $\left(d^{\prime}\right)$ revealed that the participants were equally sensi- tive for their solution decisions on lvf-RH target words $\left(d^{\prime}=2.32, S D=.84\right)$, and on rvf-LH target words $\left(d^{\prime}=\right.$ $2.37, S D=.81, t<1$ ). In prior studies (Beeman \& Bowden, 2000; Bowden \& Beeman, 1998), there was a slight rvf-LH advantage in decision accuracy. Because the participants did not first name the target words, those earlier decision data likely included more lvf-RH trials than rvfLH trials on which the participants failed to identify the target words, given that people typically are better able to read words presented to the rvf-LH than words presented to the lvf-RH.

\section{DISCUSSION}

After attempting to solve compound remote associate problems for $7 \mathrm{sec}$, the participants rated their solution decisions as more insightful when they had prior semantic activation of the solution, as indexed by solution priming. Interestingly, this association between feelings of insight and solution activation was stronger in the $\mathrm{RH}$ than in the LH. Across insight ratings, the participants showed more solution priming for lvf-RH than for rvf-LH target words and made solution decisions more quickly for lvf-RH than for rvf-LH target words, replicating earlier results (Beeman \& Bowden, 2000; Bowden \& Beeman, 1998). In addition, the current results showed that, on trials in which the target word was identified, the participants made solution decisions in the lvf-RH just as accurately as they did in the rvf-LH.

The current paradigm differs from others employed to study the subjective experience of insight (Davidson, 1995; Metcalfe, 1986a, 1986b; Metcalfe \& Wiebe, 1987) in a number of ways. Most importantly, this experiment used individual ratings of insight experience on a trial-by-trial basis. This is possible with compound remote associate problems, which sometimes evoke feelings of insight and

Table 2

Mean Solution Decision Latency (and Standard Errors, SEs) (in Milliseconds) After Naming Target Word and Accuracy Following Unsolved Problems

\begin{tabular}{|c|c|c|c|c|c|c|c|c|c|c|c|c|c|c|c|c|}
\hline \multirow[b]{3}{*}{ Dependent Variable } & \multicolumn{8}{|c|}{ rvf-LH } & \multicolumn{8}{|c|}{ lvf-RH } \\
\hline & \multicolumn{2}{|c|}{$\begin{array}{c}\text { Correct } \\
\text { Rejections }\end{array}$} & \multicolumn{2}{|c|}{$\begin{array}{c}\text { False } \\
\text { Alarm }\end{array}$} & \multicolumn{2}{|c|}{ Hit } & \multicolumn{2}{|c|}{ Miss } & \multicolumn{2}{|c|}{$\begin{array}{c}\text { Correct } \\
\text { Rejections }\end{array}$} & \multicolumn{2}{|c|}{$\begin{array}{c}\text { False } \\
\text { Alarm }\end{array}$} & \multicolumn{2}{|c|}{ Hit } & \multicolumn{2}{|c|}{ Miss } \\
\hline & $M$ & $S E$ & $M$ & $S E$ & $M$ & $S E$ & $M$ & $S E$ & $M$ & $S E$ & $M$ & $S E$ & $M$ & $S E$ & $M$ & $S E$ \\
\hline Latency & 2,152 & 150 & 2,778 & 246 & 1,942 & 119 & 2,630 & 181 & 2,114 & 135 & 2,907 & 239 & 1,833 & 113 & 2,821 & 198 \\
\hline Accuracy (\%) & 92.3 & 1.5 & & & 80.8 & 1.5 & & & 90.3 & 1.4 & & & 82.0 & 2.1 & & \\
\hline
\end{tabular}


sometimes do not. Most importantly, even if the subjective ratings system employed here is flawed, "soft," and possibly inconsistent across participants, these results link the subjective ratings to an independentmeasure (priming) of cognitive processing (semantic activation).

The fact that solvers had insight-like experiences on the same trials for which they manifested solution priming supports the position that the Aha! experience reflects, in part, prior subthreshold activation related to the solution. That is, solvers feel the Aha! experience of insight when they suddenly recognize that an already activated concept is the solution or, in more complex problems, points to the solution path. For some insight problems, solvers easily achieve solution once they recognize the solution path; for other problems, further noninsight processing is necessary after the critical insight (Dominowski \& Dallob, 1995; Schooler et al., 1995).

In our experiment, the fact that solvers manifest priming indicates that they had solution-related activation; the fact that they had not solved the problem indicates that such activation was below the threshold of awareness. When the participants saw the solution word, it was immediately recognized as the solution, leading to an Aha! experience. Note that the solution priming was measured when solvers named the solution words (a measure of lexical activation, although expectancies can also play a role at this long SOA; see Neely, 1991), so it is not the case that the insight ratings merely reflected quick solution decisions; rather, they were associated with an independent measure of semantic activation for that solution, prior to solution decision. Solution-related activation previously below the threshold of awareness could surpass that threshold, because strong misdirected activation (perhaps in the LH) may subside. Alternatively, solvers could increase solution-related activation because they may reinterpret a problem word or encounter hints or environmental cues (see, e.g., Bowden, 1997; Maier, 1931).

The results also indicate that subthreshold solution activation more often occurs in the $\mathrm{RH}$ than in the $\mathrm{LH}$, and that such RH activation is more strongly associated with the Aha! experience than is LH semantic activation. There are a few possible interpretations of this hemispheric difference in the priming-insight association. First, it is possible that subthreshold solution activation in the LH simply does not generate a feeling of insight when solvers achieve or recognize solutions. Second, it is possible that subthreshold solution activation in either hemisphere can create a feeling of insight, but that such activation is more likely to occur in the RH than in the LH. The observed lack of association between $\mathrm{LH}$ solution priming and insight ratings in this case is probabilistic: In our study, insight ratings reflected activation in either hemisphere, but hemifield priming assessed activation primarily in one hemisphere. If solution activation occurred more frequently in the $\mathrm{RH}$, as the $\mathrm{RH}$ advantage in solution priming suggests, then on some trials the participants would experience insight due to $\mathrm{RH}$ solution activation but not show priming for rvf-LH solution targets.
It is hypothetically possible that participants may consciously generate the solution in either hemisphere (although we maintain that both hemispheres normally contribute to solution generation) and take longer to verify solutions generated by the RH than by the LH. If so, RHgenerated solutions have a longer window of time during which participants are aware of the solution prior to responding. If the solution appears as a target word during this window, participants may provide a high insight rating because they were "already thinking that," partially fulfilling one of several criteria for assigning an insight rating. However, it should be noted that the insight ratings stressed many features of the Aha! experience, and the general tone implied a lack of awareness prior to the instant of recognition. Furthermore, we maintain that once solution activation rises to the point that solvers are aware of and/or attempting to verify solution candidates, this activation spreads to both hemispheres.

Thus, we conclude that the RH advantages in solution priming, ${ }^{5}$ solution decision latency, and priming-insight association all suggest that the RH plays a special role in solving insight problems and in feelings of insight. These results are consistent with the fact that hints to insight problems are more effective when presented to the lvf-RH than when presented to the rvf-LH (Fiore \& Schooler, 1998).

Both the size and the strength of activated semantic fields may contribute to these phenomena. Large semantic fields activated by RH coarse semantic coding seem better able to detect semantic overlap, as has been discussed elsewhere (for a review, see Beeman, 1998). For instance, semantic activation in the RH is more sensitive than semantic activation in the $\mathrm{LH}$ to potential connective inferences (Beeman et al., 2000) and to multiple weakly related primes (Beeman et al., 1994). For compound remote associate problems, the LH may activate the solution in connection with only one problem word and fail to detect the semantic overlap necessary to achieve solution. Then, this nonconverging activation decays in the LH, perhaps being out-competed by misdirected activation, whereas converging activation in the RH is maintained for a longer time (Beeman \& Bowden, 2000).

Solution-related activation in the RH may easily remain subthreshold, because large, diffusely activated semantic fields poorly support selection into awareness. In contrast, solution-related activation in the LH is likely to exceed threshold and reach awareness (a process we roughly refer to as selection), perhaps with a boost from attention. According to our theory, this tendency emerges due to small but strongly activated semantic fields arising from $\mathrm{LH}$ fine semantic coding. The $\mathrm{LH}$ could be as adept as the $\mathrm{RH}$ at activating solution-related information, but LH activation leads to immediate solution, whereas RH activation does not. Indeed, selecting a solution concept seems quite important in discovering insight solutions (Davidson, 1995), suggesting that the LH may be necessary for solution generation. However, in all five of our experiments in which the participants had 7 or $15 \mathrm{sec}$ to solve compound remote associate problems, the participants demonstrated 
a reliable (or nearly reliable) $\mathrm{RH}$ advantage in solution priming or in raw solution decision latency after generating solutions (Beeman \& Bowden, 2000; Bowden \& Beeman,1998; present experiment).

We are not arguing that the LH solves noninsight problems and the RH solves insight problems, or that the LH is conscious and the RH unconscious. Rather, we argue that people make conscious decisions influenced by partially independent activation in each hemisphere. We posit that action and awareness are supported by population coding - that is, the summed distributed activity of many thousands of neurons, without the need of an executive, homunculus, or grandmother cell. This population is divided over both hemispheres, and is therefore the sum of two processing styles arising, perhaps, from slightly asymmetric neural substrates: relatively fine semantic coding in the $\mathrm{LH}$ and relatively coarse semantic coding in the RH. If the LH strongly activates a narrow field of information, most of which will also be weakly activated in the RH, the information activated in the $\mathrm{LH}$ will tend to dominate the population code underlying selection of information for consciousness and responses. Contributions from the RH seem particularly important when people comprehend discourse in which initially unimportant information becomes important, such as when they draw some inferences or understand jokes (for a review, see Beeman, 1998). Because information can be shared between the hemispheres, these complementary processes are not strictly isolated from each other. However, analyzing humans' integrated awareness and action into hemispheric components can illuminate the critical processes and factors of complex behaviors such as problem solving.

\section{REFERENCES}

Beeman, M. (1993). Semantic processing in the right hemisphere may contribute to drawing inferences from discourse. Brain \& Language, 44, 80-120.

BeEmAn, M. (1998). Coarse semantic coding and discourse comprehension. In M. Beeman \& C. Chiarello (Eds.), Righthemisphere language comprehension: Perspectives from cognitiveneuroscience (pp. 255-284). Mahwah, NJ: Erlbaum.

Beeman, M. J., \& Bowden, E. M. (2000). The right hemisphere maintains solution-related activation for yet-to-be-solved insight problems. Memory \& Cognition, 28, 1231-1241.

Beeman, M. J., Bowden, E. M., \& Gernsbacher, M. A. (2000). Right and left hemisphere cooperation for drawing predictive and coherence inferences during normal story comprehension. Brain \& Language, 71, 310-336.

Beeman, M., \& Chiarello, C. (1998). Right hemisphere language comprehension: Perspectives from cognitive neuroscience. Mahwah, NJ: Erlbaum.

Beeman, M., Friedman, R. B., Grafman, J., Perez, E., Diamond, S., \& LindsaY, M. B. (1994). Summation priming and coarse semantic coding in the right hemisphere. Journal of Cognitive Neuroscience, $\mathbf{6}$, 26-45.

Bihrle, A. M., Brownell, H. H., Powelson, J. A., \& Gardner, H. (1986). Comprehension of humorous and non-humorous materials by left and right brain-damaged patients. Brain \& Cognition, 5, 399-411.

Bottini, G., Corcoran, R., Sterzi, R., Paulescu, E., Schenone, P., Scarpa, P., Frackowiak, R. S. J., \& Frith, C. D. (1994). The role of the right hemisphere in the interpretation of figurative aspects of language: A positron emission tomography activation study. Brain, 117, 1241-1253.

BowDEn, E. M. (1997). The effect of reportable and unreportable hints on anagram solution and the Aha! experience. Consciousness \& Cognition, 6, 545-573.

Bowden, E. M., \& Beeman, M. J. (1998). Getting the right idea: Semantic activation in the right hemisphere may help solve insight problems. Psychological Science, 9, 435-440.

Bowden, E. M., \& Jung-Beeman, M. (in press). Compound remote associate problems. Behavior Research Methods, Instruments, \& Computers.

Bowers, K. S., Regehr, G., Balthazard, C., \& Parker, K. (1990). Intuition in the context of discovery. Cognitive Psychology, 22, 72-110.

Brownell, H. H., Michel, D., Powelson, J. A., \& Gardner, H. (1983). Surprise but not coherence: Sensitivity to verbal humor in right hemisphere patients. Brain \& Language, 18, 20-27.

Brownell, H. H., Potter, H. H., Bihrle, A. M., \& Gardner, H. (1986). Inference deficits in right brain-damaged patients. Brain \& Language, 29, 310-321.

Brownell, H. H., Potter, H. H., Michelow, D., \& Gardner,H. (1984). Sensitivity to lexical denotation and connotation in brain-damaged patients: A double dissociation? Brain \& Language, 22, 310-321.

Burgess, C., \& Simpson, G. (1988). Hemispheric processing of ambiguous words. Brain \& Language, 33, 86-104.

Chiarello, C. (1998). On codes of meaning and the meaning of codes: Semantic access and retrieval within and between hemispheres. In M. Beeman \& C. Chiarello (Eds.), Right hemisphere language comprehension: Perspectives from cognitive neuroscience (pp. 141-160). Mahwah, NJ: Erlbaum.

Chiarello, C., Burgess, C., Richards, L., \& Pollock, A. (1990). Semantic and associative priming in the cerebral hemispheres: Some words do, some words don't, ... sometimes, some places. Brain \& Language, 38, 75-104.

COHEN, J., \& CoHEN, P. (1983). Applied multiple regression/correlation analysis for the behavioral sciences. Hillsdale, NJ: Erlbaum.

Connor, L. T., Balota, D. A., \& Neely, J. H. (1992). On the relation between feeling of knowing and lexical decision: Persistent subthreshold activation or topic familiarity? Journal of Experimental Psychology: Learning, Memory, \& Cognition, 18, 544-554.

DAvidson, J. E. (1995). The suddenness of insight. In R. J. Sternberg \& J. E. Davidson (Eds.), The nature of insight (pp. 125-156). Cambridge, MA: MIT Press.

Dominowski, R. L., \& Dallob, P. I. (1995). Insight and problem solving. In R. J. Sternberg \& J. E. Davidson (Eds.), The nature of insight (pp. 33-62). Cambridge, MA: MIT Press.

Dorfman, J., Shames, V. A., \& Kilhstrom, J. F. (1996). Intuition, incubation, and insight: Implicit cognition in problem solving. In G. Underwood (Ed.), Implicit cognition (pp. 257-296). Oxford: Oxford University Press.

Faust, M., \& Chiarello, C. (1998). Sentence context and lexical ambiguity resolution by the two hemispheres. Neuropsychologia, 36, 827836.

Faust, M., Kravetz, S., \& Babkoff, H. (1993a). Hemisphericity and top-down processing of language. Brain \& Language, 44, 1-18.

Faust, M., Kravetz, S., \& BabKoff, H. (1993b). Hemispheric specialization or reading habits: Evidence from lexical decision research with Hebrew words and sentences. Brain \& Language, 44, 254-263.

Faust, M. E., \& Gernsbacher, M. A. (1996). Cerebral mechanisms for suppression of inappropriate information during sentence comprehension. Brain \& Language, 53, 234-259.

Fiore, S. M., \& Schooler, J. W. (1998). Right hemisphere contributions to creative problem solving: Converging evidence for divergent thinking. In M. Beeman \& C. Chiarello (Eds.), Right hemisphere language comprehension: Perspectives from cognitive neuroscience (pp. 349-371). Mahwah, NJ: Erlbaum.

Gick, M. L., \& LocKhart, R. S. (1995). Cognitive and affective components of insight. In R. J. Sternberg \& J. E. Davidson (Eds.), The nature of insight (pp. 197-228). Cambridge, MA: MIT Press.

KoIvisto, M. (1997). Time course of semantic activation in the cerebral hemispheres. Neuropsychologia, 35, 497-504.

MAIER, N.R. F. (1931). Reasoning in humans II: The solution of a problem and its appearance in consciousness. Journal of Comparative Psychology, 12, 181-194.

Mednick, S. A. (1962). The associative basis of the creative process. Psychological Review, 69, 220-232. 
MetCALFe, J. (1986a). Feeling of knowing in memory and problem solving. Journal of Experimental Psychology: Learning, Memory, \& Cognition, 12, 288-294.

Metcalfe, J. (1986b). Premonitions of insight predict impending error. Journal of Experimental Psychology: Learning, Memory, \& Cognition, 12, 623-634.

Metcalfe, J. \& Wiebe, D. (1987). Intuition in insight and noninsight problem solving. Memory \& Cognition, 15, 238-246.

NAKAGAWA, A. (1991). Role of anterior and posterior attention networks in hemispheric asymmetries during lexical decisions. Journal of $\mathrm{Cog}_{-}$ nitive Neuroscience, 3, 315-321.

NeELY, J. H. (1991). Semantic priming effects in visual word recognition: A selective review of current findings and theories. In D. Besner \& J. W. Humphreys (Eds.), Basic processes in reading: Visual word recognition (pp. 264-336). Hillsdale, NJ: Erlbaum.

OHLSSON, S. (1992). Information-processing explanations of insight and related phenomena. In M. Keane \& K. Gilhooley (Eds.), Advances in the psychology of thinking (pp. 1-44). London: Harvester-Wheatsheaf.

Robertson, D. A., Gernsbacher, M. A., Guidotti, S. J., Robertson, R. R. W., Irwin, W., Mock, B. J., \& CAMPana, M. E. (2000). Functional neuroanatomy of the cognitive process of mapping during discourse comprehension. Psychological Science, 11, 255-260.

Schooler, J. W., Fallshore, M., \& Fiore, S. M. (1995). Epilogue: Putting insight into perspective. In R. J. Sternberg \& J. E. Davidson (Eds.), The nature of insight (pp. 559-587). Cambridge, MA: MIT Press.

Schooler, J. W., \& Melcher, J. (1995). The ineffability of insight. In S. M. Smith \& T. B. Ward (Eds.), The creative cognition approach (pp. 97-133). Cambridge, MA: MIT Press.

Schooler, J. W., Ohlsson, S., \& Brooks, K. (1993). Thoughts beyond words: When language overshadows insight. Journal of Experimental Psychology: General, 122, 166-183.

Seifert, C. M., Meyer, D. E., Davidson, N., Patalano, A. L., \& YANIV, I. (1995). Demystification of cognitive insight: Opportunistic assimilation and the prepared-mind perspective. In R. J. Sternberg \& J. E. Davidson (Eds.), The nature of insight (pp. 65-124). Cambridge, MA: MIT Press.

SMITH, S. M. (1995). Getting into and out of mental ruts: A theory of fixation, incubation, and insight. In R. J. Sternberg \& J. E. Davidson (Eds.), The nature of insight (pp. 229-252). Cambridge, MA: MIT Press.

St. George, M. Kutas, M., Martinez, A., \& Sereno, M. I. (1999). Semantic integration in reading: Engagement of the right hemisphere during discourse processing. Brain, 122, 1317-1325.
Titone, D. (1998). Hemispheric differences in context sensitivity during lexical ambiguity resolution. Brain \& Language, 65, 361-394.

WinNer, E, \& GARDNER, H. (1977). The comprehension of metaphor in brain-damaged patients. Brain, 100, 719-727.

YANIV, I., \& MEYER, D. E. (1987). Activation and metacognition of inaccessible stored information: Potential bases for incubation effects in problem solving. Journal of Experimental Psychology: Learning, Memory, \& Cognition, 13, 187-205.

\section{NOTES}

1. Hemifield effects with Hebrew stimuli demonstrate that direction of reading affects neither the basic rvf-LH advantage in reading words (M. Faust, Kravetz, \& Babkoff, 1993b) nor the patterns of semantic priming across the hemifields/hemispheres (M. Faust, Kravetz, \& Babkoff, 1993a).

2. The rating scale appeared on all trials regardless of whether the participants indicated that the target word was the solution or was not the solution. This was done so that the appearance of the rating scale did not give the participants feedback about the accuracy of their solution decisions. Only ratings and data from trials on which the participants made hits (correctly accepting solutions) after failing to solve the problems were analyzed.

3. It is possible that some participants solved the problem in the interval between the offset of the problem triad and the onset of the target word. However, on average, the participants solved 2.1 problems in the final $750 \mathrm{msec}$ of the 7 -sec time limit. Only half of these (i.e., 1 problem) should be followed by a solution target, and this could not have a great influence on the average RT. Moreover, such solutions should occur with equal frequency prior to lvf-RH and rvf-LH target words, and so cannot explain differential priming in the hemifields.

4. Priming scores at all rating points were derived using the common baseline of latencies for all unrelated words within each hemifield, because insight ratings for unrelated words would not be meaningful.

5. A "ceiling effect" is unlikely to be limiting priming for rvf- $\mathrm{LH}$ targets, given that (1) the participants responded equally fast to solution words presented in both hemifields, (2) naming times were relatively slow in comparison with single-word priming paradigms, and (3) rvf-LH advantages in priming have been documented with other prime types.

(Manuscript received May 2, 2000; revision accepted for publication July 10, 2002.) 